\title{
5G Connected Autonomous Vehicle Acceptance: The Mediating Effect of Trust in the Technology Acceptance Model
}

\author{
Wai Mun Chan \\ Faculty of Business and Management, UCSI University, Kuala Lumpur, Malaysia \\ Jason Wai Chow Lee \\ Faculty of Business and Management, UCSI University, Kuala Lumpur, Malaysia
}

\begin{abstract}
The purpose of this paper is to examine the factors that influence the behavioural intention towards $5 \mathrm{G}$ connected autonomous vehicle (CAV) adoption and to examine the mediating effect of trust between the factors and public acceptance. This research has adopted the Technology Acceptance Model (TAM) and Unified Theory of Acceptance and Use of Technology (UTAUT) framework. To test the hypotheses, 211 participants in Malaysia were surveyed through an online questionnaire. The results were tested using PLS-SEM. The research model was able to explain about $69 \%$ of the variability in technology acceptance. The results show that perceived compatibility and personal innovativeness significantly influence behavioural intention. Trust was found to mediate the relationship between perceived usefulness, perceived ease of use and social influence with behavioural intention to adopt $5 \mathrm{G}$ CAV. This paper will help the automobile industry and policymakers to accelerate the development of 5G CAV technology by anticipating the level of acceptance.
\end{abstract}

Keywords: Autonomous vehicle, Technology Acceptance Model, Unified Theory of Acceptance and Use of Technology, Self-driving Vehicle, Trust. 


\section{Introduction}

The emergence of fifth-generation wireless technology (5G) was expected to bring enormous technological advancement to the autonomous vehicle industry. $5 \mathrm{G}$ wireless technology is expected to connect almost everything around us with an ultra-fast, highly reliable, and fully responsive communication network. It will allow communications to be much faster, ubiquitous, and more reliable due to its high speed, low latency, massive connectivity and improved network coverage (Rendon et al., 2019; Zhang et al., 2019). With 5G technology, autonomous vehicles will move closer to becoming a reality. Automobile companies like Audi, BMW, Ford Motor, General Motors, Honda, Hyundai, Nissan, Volvo and Volkswagen are in a race to build autonomous vehicles that would radically change the consumer world (Shankland, 2019). Moreover, with technology pioneers like Google, Tesla, and Uber joining the race, the impact will drive the autonomous industry to become more mature (Chehri \& Mouftah, 2019).

Autonomous vehicles (AV) can perceive what is going on in their surroundings and travel to different locations through a combination of sensors, cameras, radar and artificial intelligence (Chehri \& Mouftah, 2019; Zhao et al., 2018). By leveraging the high speed and fast response of $5 \mathrm{G}$ technology, connected autonomous vehicles (CAV) can communicate with nearby vehicles and the infrastructure around them through vehicle-to-anything (V2X) communications (Shankland, 2019; Zhang et al., 2019). V2X communication allows autonomous vehicles to collect and receive information (like obstacles, accidents, weather and road conditions, and objects moving near the car, etc.) all at once over a network through hundreds of sensors. Jane Rygaard, the head of Nokia's marketing and advanced mobile networks solutions, stated that it takes time for the message to be transmitted between sensors and then get to the computer for decision making. This should be less than a human would take to make a decision, which is 2 milliseconds. The current $4 \mathrm{G}$ speed is insufficient to provide autonomous car systems with human-like reflexes, which may have avoided Uber's fatal accident (Yu \& Petnga, 2018; Llanasas, 2019). The enormous amount of information requires a fast and reliable network to transmit the data between sensors and in-car computers; thus, 5G networks will be the key-enabler in managing the safety challenges of vehicle automation (BBC News, 2019; McKinsey \& Company, 2019).

According to the report co-published by the World Economic Forum (WEF), MIT Media Lab, and Boston Consulting Group (BCG) in 2017, the emergence of the autonomous vehicle industry is expected to reduce the number of cars on the road by $28 \%$, reducing average travel time by $30 \%$, reducing carbon emissions by $66 \%$, reducing the parking spaces required by $48 \%$, and reducing traffic-related accidents by 87\% globally (Aptiv, 2019; World Economic Forum, 2019). This is also supported by prior studies that CAV technology could help reduce road accident and traffic congestion (Shin et al., 2019; Martínez-Díaz and Soriguera, 2018; Rahman et al., 2018). The availability of $5 \mathrm{G}$ networks would make it possible to strengthen the capabilities of the CAV technologies by removing human error in road accidents. An estimated 1.25 million people lost their lives in traffic accidents around the world annually (Wegman, 2017). The consequences of crashes and casualties resulted in a loss in the gross domestic product (GDP) between 1 to 5 percent to a country. For example, traffic crashes and casualties result in estimated losses of MYR 9 billion every year, affecting the social economics in Malaysia (Road Safety Department of Malaysia, 2014, Eusofe and Evdorides, 2017). While autonomous technology has grown exponentially over the 
years, some key challenges, like technological development, regulation, government support, and ultimately, public acceptance are keeping the technology from being fully commercialized (Zhang et al., 2019; World Economic Forum, 2019).

Hence, the current study aims to identify some of the key factors that influence the behavioural intention towards the adoption of 5G CAV. Quite often, people develop trust in a given technology if they believe it will pose them no harm and risk (Amaro \& Duarte, 2015; Sinha \& Mukherjee, 2016). Given this focus, it was of particular interest to determine whether trust mediates CAV acceptance in Malaysia. This research focuses on the following questions:

1. How does perceived usefulness, perceived ease of use, perceived compatibility, social influence and personal innovativeness affect an individual's intention to use $5 \mathrm{G} \mathrm{CAV?}$

2. Does trust mediate the effects of perceived usefulness, perceived ease of use, perceived compatibility, social influence and personal innovativeness on an individual's intention to use 5G CAV?

This research sets out to make several contributions. Prior studies found high acceptance of autonomous vehicles in various countries like the United States, China, Japan and parts of Europe (Koul \& Eydgahi, 2018; Park et al.,2018, Zhao et al., 2018; Penmetsa et al., 2019; Raue et al., 2019; Shin et al., 2019). However, there was a lack of studies related to autonomous vehicles in Malaysia. This study aims to help current and future researchers in conducting a similar study related to this subject.

Next, this study will be helpful to the automotive industry, as they may be interested in some of the key concerns that users are looking for in this technology. Since a decade ago, due to the increased interest in environmental issues, especially carbon emissions, manufacturers have focused on developing more economical and efficient transportation to replace traditional vehicles (Park et al., 2018). However, manufacturers like Tesla and Uber cannot agree on what users need and want in an autonomous vehicle. As a result, there are no unification standards in technology development (Hewitt et al., 2019). Therefore, understanding users' perceptions of the technology could help manufacturers in their decision-making and strategize the development of future autonomous vehicles (Penmetsa et al., 2019).

\section{Literature Review and Hypotheses Development}

Figure 1: Technology Acceptance Model (TAM)

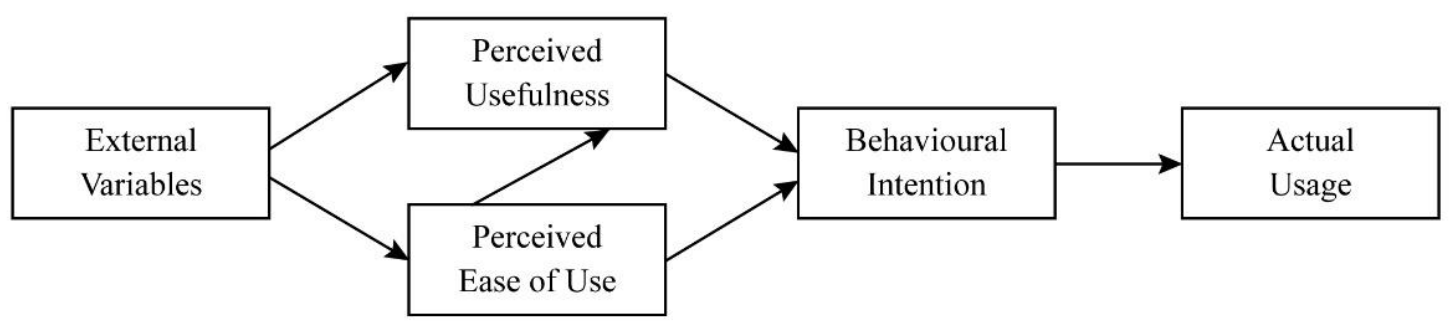




\section{Theories of Technology Acceptance}

TAM (Figure 1) was introduced by Fred Davis in 1986 to explain the relationship between the perceived ease of use and perceived usefulness of user acceptance in information systems (Davis et al., 1989; Davis \& Venkatesh, 1996). TAM was an adaption of the theory of reasoned action (TRA), a general model that has proven successful in predicting and explaining behaviour across all domains (Davis et al., 1989). TAM was accepted as one of the most effective and widely used information system theoretical frameworks (Koul \& Eydgahi, 2018). For example, TAM has been applied in various settings, such as online learning, mobile commerce, joint humanautomation technology, agricultural services systems, smartphones, and driverless car technology. A variety of studies suggest the TAM framework to determine user acceptance of new and emerging technologies (Davis \& Venkatesh, 1996; Gao \& Bai, 2014; Park et al., 2018; Koul \& Eydgahi, 2018; Raue et al., 2019). Various researchers have used the TAM framework and added new constructs and relationships to describe user acceptance (Ghazizadeh et al., 2012; Rahman et al., 2018).

The UTAUT model was developed by Venkatesh et al. (2003) through the adoption of several models of technology acceptance and human behaviour, including TAM and TRA. UTAUT considered four constructs (performance expectancy, effort expectancy, social influence, and facilitating conditions) to have significant roles in user acceptance. The UTAUT framework has been used to assess the acceptance of driver support systems technologies by incorporating constructs like compatibility, trust and personal innovativeness (Rahman et al., 2018). Other studies have found the support role of social influence and trust as determinants of the acceptance of driverless vehicles (Nordhoff et al., 2018). Therefore, the above-mentioned theories of technology acceptance are suitable in developing a framework for user acceptance of $5 \mathrm{G} \mathrm{CAV}$.

\section{Behavioural Intention to Use 5G CAV}

An autonomous vehicle, also referred to as a self-driving or driverless vehicle, is a vehicle, which, upon start-up, will operate without human intervention, using computerized systems to detect and collect information of the surrounding environment (like traffic lights, road, signage, obstacles). The information will be processed and used by the vehicle to control the responsive actions of the vehicle (like steering, acceleration and braking) to navigate the vehicle safely (Hulse et al., 2018).

Din et al. (2019) suggested that 5G technology integration with several IoT technologies used for traffic management, like intelligent transportation systems (ITS) will significantly improve the traffic and safety conditions on the road. The fifthgeneration wireless technology $(5 \mathrm{G})$ is expected to play an important role by enhancing the data rates through low latency in the network communication (Tian et al., 2018; Din et al., 2019; Rendon Schneir et al., 2019). Two connectivity requirements are needed for the future vehicle: network-based and direct communication. A network-based communication enables the vehicle to use a cellular network like $5 \mathrm{G}$ to communicate with nearby vehicles and the infrastructure around them. A direct network allows vehicles to communicate directly with their nearby surroundings without relying on cellular networks. Network-based technology requires ubiquitous and reliable networks in urban areas and low latency to ensure smooth control (McKinsey \& Company, 2019). An example of network-based communication is vehicle-to-vehicle (V2V) or vehicle- 
to-infrastructure (V2I) and vehicle-to-everything (V2X) communication (Chehri \& Mouftah, 2019; Din et al., 2019).

\section{Perceived Usefulness and Perceived Ease of Use}

This study adopted the popular constructs (perceived usefulness and perceived ease of use) from the TAM framework to explain technology acceptance. Perceived usefulness (PU) refers to the degree to which an individual believes that using a particular technology would enhance their performance (Davis, 1989; Venkatesh et al., 2003). Meanwhile, perceived ease of use (PEOU) refers to the degree to which an individual believes that using a particular technology would be free of effort (Davis, 1989; Venkatesh et al., 2003). Prior studies suggest that the TAM constructs can be employed to predict user acceptance in various new IT technologies (Gao \& Bai, 2014). The CAV is expected to bring more benefits to users in terms of road safety, reduced traffic and reduced energy consumptions that will eventually lead to a higher acceptance of the technology (Zhang et al., 2019; Hulse et al., 2018; Koul \& Eydgahi, 2018). It is worth noting that the existing CAV technology does not have a standard architecture design (Hewitt et al., 2019). Therefore, PEOU will greatly affect behavioural intention, as the user may have high expectations on how to operate or navigate a CAV. Thus, we hypothesize that:

H1 Perceived usefulness has a positive effect on an individual's intention to use 5G CAV.

$\mathrm{H} 2$ Perceived ease of use has a positive effect on an individual's intention to use $5 \mathrm{G} \mathrm{CAV}$.

\section{Perceived Compatibility}

Perceived compatibility (PC) was defined as the degree to which an innovation is perceived as being consistent with the existing values, needs, and past experiences of potential adopters (Moore \& Benbasat, 1991; Rahman et al., 2018). Compatibility measures a technology's consistency with an individual's preferred work style, existing work practices, values, experience, and needs (Ghazizadeh et al., 2012). For instance, a study on mobile payment usage in Austria was found to positively affect an individual's intention to use it if the technology suited their values, needs and experiences (Schmidthuber et al., 2018). Similarly, compatibility has a significant effect on the consumer adoption of driver support systems (Rahman et al., 2018). Ghazizadeh et al. (2012) suggest that prior experience with similar technology (in this case, the CAV) may affect greater acceptance. Therefore, we examine the following hypothesis:

H3 Perceived compatibility has a positive effect on an individual's intention to use 5G CAV.

\section{Social Influence}

Social influence (SI) from peers, family, and media were found to influence a user's intention to adopt a given technology (Gao \& Bai, 2014). Venkatesh et al. (2003) and Rahman et al. (2018) proposed that SI is the degree to which an individual perceives 
that important others believe he or she should use the new system. Earlier studies found that social influence has a positive relationship with consumers' intention to use mobile payment (Schmidthuber et al., 2018). In the CAV context, the influence of others like family and friends will increase the likelihood that an individual will adopt CAV technology (Panagiotopoulos \& Dimitrakopoulos, 2018). Therefore, the following hypothesis is included:

H4 Social influence has a positive effect on an individual's intention to use 5G CAV.

\section{Personal Innovativeness}

Personal innovativeness (PI) refers to the willingness of an individual to adopt an innovation earlier than others (Rahman et al., 2018). Turan et al. (2015) conceptualized that an individual is considered innovative when they adopt an innovation relatively earlier than others. An individual with higher personal innovativeness often develops stronger acceptance of new ideas and technological systems (Lu et al., 2005). A prior study found that personal innovativeness has a positive relationship with a consumer's intention to use mobile payment in European countries (Schmidthuber et al., 2018). Since CAV is a developing technology, we test the following hypothesis:

H5 Personal innovativeness has a positive effect on an individual's intention to use 5G CAV.

\section{The Role of Trust as a Mediator}

Trust (TR) was defined as the degree of beliefs about predictability and functionality of system characteristics (Herrenkind et al.,2019). Several researchers suggested that trust has a positive influence on a user's intention to adopt new technology (Gao \& Bai, 2014; Amaro \& Duarte, 2015; Choi \& Ji, 2015; Kaur \& Rampersad, 2018; Khastgir et al., 2018; Singh \& Sinha, 2020). CAV technology that is reliable, convenient, easy to use and navigate will help build trust. Chawla \& Joshi (2020) found that perceived usefulness and perceived ease of use positively increase a customer's trust in mobile technology. In this study, a respondent may reply differently, as they do not have real interaction experience with $\mathrm{CAV}$ as opposed to existing technology like a mobile wallet. Gao \& Bai (2014) suggested that social influence has a positive effect on user acceptance. Additionally, Panagiotopoulos \& Dimitrakopoulos (2018) implied that the more we trust the autonomous vehicle, the less likely we will be influenced by the social norm. Findings from Rahman et al. (2018) show the direct association between compatibility, trust, personal innovativeness and intention to use. However, there were no studies to suggest the relationship between perceived compatibility and personal innovativeness with trust. Hence, we examine the following hypotheses:

H1a Perceived usefulness has a positive effect on an individual's trust in 5G CAV.

H2a Perceived ease of use has a positive effect on an individual's trust in 5G CAV.

H3a Perceived compatibility has a positive effect on an individual's trust in 5G CAV.

H4a Social influence has a positive effect on an individual's acceptance of 5G CAV. 
H5a Personal innovativeness has a positive effect on an individual's trust in 5G CAV.

H6 Trust has a positive effect on an individual's intention to use 5G CAV.

We extend the current research by examining trust as a mediator in the relationship between factors that influence technology acceptance and behavioural intention. Singh $\&$ Sinha (2020) found a partial mediating effect of trust on perceived usefulness and mobile wallet acceptance in India. The authors conclude that users are less likely to trust a technology that is not useful. In the context of autonomous vehicles, to our best knowledge, no study examines the mediating effect of trust between perceived compatibility, social influence and personal innovativeness with behavioural intention. Therefore, we propose the following hypotheses:

H7a Trust mediates the effects of perceived usefulness on an individual's intention to use $5 \mathrm{G} \mathrm{CAV}$.

H7b Trust mediates the effects of perceived ease of use on an individual's intention to use $5 \mathrm{G} \mathrm{CAV}$.

H7c Trust mediates the effects of perceived compatibility on an individual's intention to use $5 \mathrm{G} \mathrm{CAV}$.

H7d Trust mediates the effects of social influence on an individual's intention to use $5 \mathrm{G} \mathrm{CAV}$.

H7e Trust mediates the effects of personal innovativeness on an individual's intention to use $5 \mathrm{G} \mathrm{CAV}$.

\section{Research Model of the Study}

Figure 2 show the research model of this study. The popular constructs, perceived usefulness and perceived ease of use were adapted from the TAM framework. The construct, social influence, was also adapted from the UTAUT framework. The technology acceptance model was extended by including the constructs, perceived compatibility and personal innovativeness. Finally, trust was included as the mediator to find the relationships between the constructs and behavioural intention to use $5 \mathrm{G}$ CAV. 
Figure 2: Research Framework

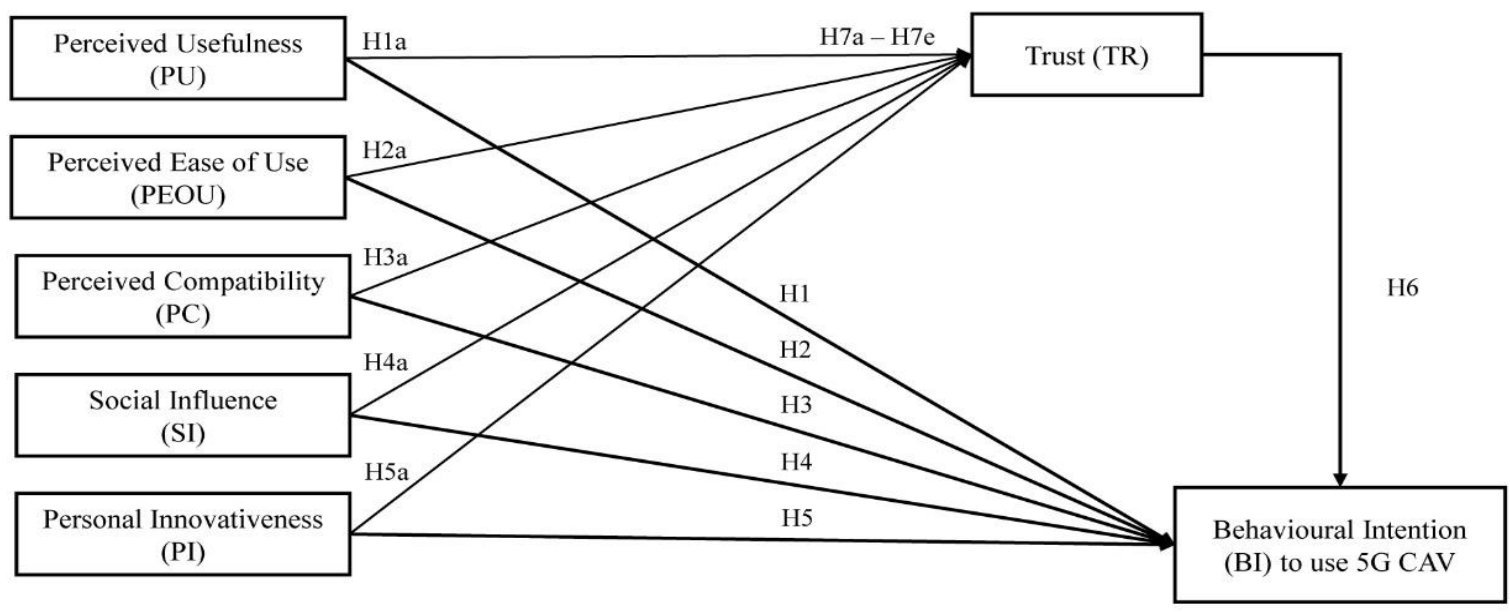

\section{Research Methodology}

The main focus of this research is to examine factors that influence the behavioural intention towards 5G CAV adoption. The target population of this study was respondents residing in Malaysia with prior knowledge of 5G technology and autonomous vehicles. Prior researchers suggested an adequate sample size of 200 is fair and recommended for an accurate study (Comrey \& Lee, 1992; Tabachnick \& Fidell, 2007). A sample size of 211 was collected for this study.

A cross-sectional study was conducted using quantitative research through a survey strategy. The survey was hosted online using Google Forms (https://www.google.com/forms/about/). A sub-section at the beginning of the survey explains the background of the study. Photos and video media of the autonomous driving bus "Xiaoyu" manufactured by Yutong Group in China were shown to ensure that respondents had an idea of how 5G CAV technology works (China Car News, 2019, New China TV, 2019). This method is similar to the approach used by Nordhoff et al. (2018) to examine the respondents' willingness to adopt driverless cars. A fivepoint Likert scale was used to measure the variables, ranging from strongly disagree (1) to strongly agree (5). The survey was conducted anonymously, and respondents were briefed on the data privacy and protection of their personal information. The PLS-SEM technique was applied for data analysis and testing of hypotheses. 
Table 1: Conceptual and Operational Definitions of Constructs

\begin{tabular}{|c|c|c|c|}
\hline Construct & Operational Definition & Items & Source \\
\hline $\begin{array}{l}\text { Perceived } \\
\text { usefulness (PU) }\end{array}$ & $\begin{array}{l}\text { "The degree to which a person believes that } \\
\text { using a system would be free of effort." }\end{array}$ & 5 & $\begin{array}{l}\text { Davis (1989); } \\
\text { Venkatesh et al. } \\
\text { (2003) }\end{array}$ \\
\hline $\begin{array}{l}\text { Perceived Ease } \\
\text { of use (PEOU) }\end{array}$ & $\begin{array}{l}\text { "The degree to which using an innovation is } \\
\text { perceived as being difficult to use." }\end{array}$ & 5 & $\begin{array}{l}\text { Davis (1989); } \\
\text { Venkatesh et al. } \\
\text { (2003) }\end{array}$ \\
\hline $\begin{array}{l}\text { Perceived } \\
\text { Compatibility } \\
\text { (PC) }\end{array}$ & $\begin{array}{l}\text { "The degree to which an innovation is } \\
\text { perceived as being consistent with the } \\
\text { existing values, needs, and past experiences } \\
\text { of potential adopters." }\end{array}$ & 3 & $\begin{array}{l}\text { Moore \& } \\
\text { Benbasat } \\
\text { (1991); } \\
\text { Rahman et al. } \\
(2018)\end{array}$ \\
\hline $\begin{array}{l}\text { Social Influence } \\
\text { (SI) }\end{array}$ & $\begin{array}{l}\text { "The degree to which an individual perceives } \\
\text { that important others believe he or she should } \\
\text { use the new system." }\end{array}$ & 6 & $\begin{array}{l}\text { Schierz et al. } \\
(2010) \text {; } \\
\text { Rahman et al. } \\
(2018)\end{array}$ \\
\hline $\begin{array}{l}\text { Personal } \\
\text { Innovativeness } \\
\text { (PI) }\end{array}$ & $\begin{array}{l}\text { "The willingness to adopt (technology) } \\
\text { innovations earlier than others." }\end{array}$ & 5 & $\begin{array}{l}\text { Rahman et al. } \\
\text { (2018) }\end{array}$ \\
\hline Trust (TR) & $\begin{array}{l}\text { "The degree of beliefs about predictability } \\
\text { and functionality of system characteristics." }\end{array}$ & 6 & $\begin{array}{l}\text { Herrenkind et } \\
\text { al. (2019) }\end{array}$ \\
\hline
\end{tabular}

\section{Results and Findings}

\section{Demographic Analysis}

The demographic of respondents $(\mathrm{N}=211)$ is summarized in Table 2. The questionnaire survey consists of 7 demographic items, which can be categorized as gender, age, ethnicity, education level, occupation, monthly income and the state they are currently living.

Table 2 shows that $55.5 \%$ of respondents are male, and the remaining $44.5 \%$ are female. It also revealed that those aged less than 39 years are $81.1 \%, 40-54$ years are $17.5 \%$ and those above 55 years are $1.4 \%$. The majority of the respondents are Chinese, who accounted for $84.8 \%$, while the rest of the ethnicity group are Malay, Indian and other ethnicities recorded as $10.4 \%, 2.8 \%$ and $1.9 \%$, respectively. The highest educational level is $58.3 \%$ for degree level, $12.3 \%$ for primary/secondary school or lower level, $18.5 \%$ for pre-university/diploma level and $10.9 \%$ for master/Ph.D/ or higher level, respectively. Private company employees (58.3\%), self-employed entrepreneurs $(18.5 \%)$ and professionals $(10.9 \%)$ are among the largest contributors to the occupation group. It is discovered that the average income of respondents is below RM8000, which accounts for $69.2 \%$. Finally, the majority of respondents reside in Wilayah Persekutuan Kuala Lumpur (44.1\%) and Selangor (39.8\%). 
Table 2: Demographic of Respondents

\begin{tabular}{|c|c|c|c|}
\hline Variables & Category & Frequency & Percentage $(\%)$ \\
\hline \multirow[t]{2}{*}{ Gender } & Female & 94 & 44.5 \\
\hline & Male & 117 & 55.5 \\
\hline \multirow{4}{*}{ Age } & less than 25 & 17 & 8.1 \\
\hline & 25 - 39 years old & 154 & 73.0 \\
\hline & 40 - 54 years old & 37 & 17.5 \\
\hline & 55 years old and above & 3 & 1.4 \\
\hline \multirow[t]{4}{*}{ Ethnicity } & Malay & 22 & 10.4 \\
\hline & Chinese & 179 & 84.8 \\
\hline & Indian & 6 & 2.8 \\
\hline & Other & 4 & 1.9 \\
\hline Education & Primary / Secondary school or lower & 26 & 12.3 \\
\hline \multirow[t]{3}{*}{ Level } & Pre-University/ Diploma & 39 & 18.5 \\
\hline & Degree & 123 & 58.3 \\
\hline & Master / Ph.D or higher & 23 & 10.9 \\
\hline \multirow[t]{8}{*}{ Occupation } & Professionals & 23 & 10.9 \\
\hline & $\begin{array}{l}\text { (Lawyer/Doctor/Accountant/ } \\
\text { Researcher/Professor/Teacher) }\end{array}$ & & \\
\hline & Government officer & 3 & 1.4 \\
\hline & Private company staff & 123 & 58.3 \\
\hline & Self-employed/ businessman & 39 & 18.5 \\
\hline & Unemployed & 1 & 0.5 \\
\hline & Student & 20 & 9.5 \\
\hline & Housewife & 2 & 0.9 \\
\hline \multirow{7}{*}{$\begin{array}{l}\text { Monthly } \\
\text { Income }\end{array}$} & RM 2,000 and below & 36 & 17.1 \\
\hline & Between RM2,000 - RM4,999 & 48 & 22.7 \\
\hline & Between RM5,000 - RM7,999 & 62 & 29.4 \\
\hline & Between RM8,000 - RM10,999 & 55 & 26.1 \\
\hline & Between RM11,000 - RM13,999 & 0 & 0.0 \\
\hline & Between RM14,000 - RM16,999 & 3 & 1.4 \\
\hline & RM17,000 and above & 7 & 3.3 \\
\hline \multirow{15}{*}{$\begin{array}{l}\text { State of } \\
\text { staying }\end{array}$} & Johor & 7 & 3.3 \\
\hline & Kedah & 3 & 1.4 \\
\hline & Kelantan & 0 & 0.0 \\
\hline & Melaka & 3 & 1.4 \\
\hline & Negeri Sembilan & 1 & 0.5 \\
\hline & Pahang & 1 & 0.5 \\
\hline & Perak & 1 & 0.5 \\
\hline & Perlis & 0 & 0.0 \\
\hline & Pulau Pinang & 14 & 6.6 \\
\hline & Sabah & 2 & 0.9 \\
\hline & Sarawak & 2 & 0.9 \\
\hline & Selangor & 84 & 39.8 \\
\hline & Terengganu & 0 & 0.0 \\
\hline & WP Kuala Lumpur & 93 & 44.1 \\
\hline & WP Putrajaya & 0 & 0.0 \\
\hline
\end{tabular}

\section{Measurement Model Assessment}

A measurement model assessment was conducted to test the validity and reliability of all the constructs in the research framework. Typically, assessing the measurement model involves establishing convergent validity and discriminant validity. Convergent validity is established when the factor loadings of all the indicator items for each 
construct are above 0.70 , and the composite reliability (CR) is more than 0.70 , while the average variance extracted is more than 0.50 . Table 3 shows tests of the convergent validity of the constructs. All the factor loadings are above 0.70 , and the composite reliability (CR) of all the constructs is greater than 0.70 , while the average variance is extracted (AVE). Since factor loadings, CR and AVE have met the conditions for convergent validity; the measurement model has established convergent validity (Hair et al., 2014).

Table 3: Convergent Validity

\begin{tabular}{|c|c|c|c|c|}
\hline Constructs & Items & Loadings & CR & AVE \\
\hline \multirow[t]{5}{*}{ Behavioural Intention (BI) } & BI1 & 0.889 & 0.960 & 0.829 \\
\hline & $\mathrm{BI} 2$ & 0.950 & & \\
\hline & $\mathrm{BI} 3$ & 0.947 & & \\
\hline & BI4 & 0.875 & & \\
\hline & BI5 & 0.887 & & \\
\hline \multirow[t]{3}{*}{ Perceived compatibility (PC) } & PC1 & 0.905 & 0.922 & 0.798 \\
\hline & PC2 & 0.876 & & \\
\hline & PC3 & 0.899 & & \\
\hline \multirow[t]{5}{*}{ Perceived ease of use (PEOU) } & PEOU1 & 0.860 & 0.892 & 0.624 \\
\hline & PEOU2 & 0.763 & & \\
\hline & PEOU3 & 0.793 & & \\
\hline & PEOU4 & 0.739 & & \\
\hline & PEOU5 & 0.790 & & \\
\hline \multirow[t]{5}{*}{ Personal innovativeness (PI) } & PI1 & 0.756 & 0.901 & 0.646 \\
\hline & PI2 & 0.705 & & \\
\hline & PI3 & 0.863 & & \\
\hline & PI4 & 0.829 & & \\
\hline & PI5 & 0.854 & & \\
\hline \multirow[t]{3}{*}{ Perceived usefulness (PU) } & PU1 & 0.835 & 0.838 & 0.564 \\
\hline & PU2 & 0.789 & & \\
\hline & PU3 & 0.787 & & \\
\hline \multirow[t]{3}{*}{ Social influence (SI) } & SI4 & 0.919 & 0.925 & 0.756 \\
\hline & SI5 & 0.946 & & \\
\hline & SI6 & 0.942 & & \\
\hline \multirow[t]{6}{*}{ Trust (TR) } & TR1 & 0.875 & 0.961 & 0.803 \\
\hline & TR2 & 0.845 & & \\
\hline & TR3 & 0.907 & & \\
\hline & TR4 & 0.903 & & \\
\hline & TR5 & 0.925 & & \\
\hline & TR6 & 0.918 & & \\
\hline
\end{tabular}

\section{Discriminant Validity}

When a construct is unique and distinct from other constructs in a model, discriminant validity is established. The Heterotrait-Monotrait (HTMT) test was applied to establish the discriminant validity of all the constructs. Table 4 presents the HTMT test for discriminant validity. The cut-off point for all HTMT values should be less than 0.85 
(Hair et al., 2017). Since all the HTMT values in Table 4 are less than 0.85, discriminant validity was established in this study.

Table 4: Discriminant Validity using HTMT

\begin{tabular}{llllllll}
\hline & $\mathbf{1}$ & $\mathbf{2}$ & $\mathbf{3}$ & $\mathbf{4}$ & $\mathbf{5}$ & $\mathbf{6}$ & $\mathbf{7}$ \\
\hline 1. BI & & & & & & & \\
2. PC & 0.765 & & & & & & \\
3. PEOU & 0.686 & 0.763 & & & & & \\
4. PI & 0.649 & 0.717 & 0.67 & & & & \\
5. PU & 0.679 & 0.621 & 0.715 & 0.536 & & & \\
6. SI & 0.62 & 0.758 & 0.594 & 0.611 & 0.553 & & \\
7. TR & 0.793 & 0.698 & 0.705 & 0.591 & 0.840 & 0.676 & \\
\hline
\end{tabular}

Note: $\mathrm{BI}=$ behavioural intention; $\mathrm{PC}=$ perceived compatibility; $\mathrm{PEOU}=$ perceived ease of use; $\mathrm{PI}=$ personal innovativeness; $\mathrm{PU}=$ perceived usefulness; $\mathrm{SI}=$ social influence; $\mathrm{TR}=$ trust

\section{Structural Model Assessment}

An algorithm was used to determine the construct scores, path coefficients and the $\mathrm{R}^{2}$ values when assessing the structural model. Bootstrapping was conducted to determine the $\mathrm{t}$-values and to test the proposed hypotheses. The $\mathrm{R}^{2}$ for behavioural intention (BI) was 0.687 and 0.669 for trust. This means that PC, PEOU, PI, PU, SI and TR could explain about $69 \%$ of the variance in BI and about $67 \%$ in TR.

Table 5 presents the results of the hypothesis tests. TR $(\beta=0.463, p<0.001)$ significantly impact on BI, PI $((\beta=0.145, p<0.05)$, and PC $(\beta=0.271, p<0.01)$ was positively related to BI. This shows a positive relationship between trust, personal innovativeness and perceived compatibility with behavioural intention to use $5 \mathrm{G} \mathrm{CAV}$.

Next, contrary to the findings from past researchers (Davis, 1989; Venkatesh et al., 2003; Gao \& Bai, 2014; Koul \& Eydgahi, 2018; Schmidthuber et al., 2018; Panagiotopoulos \& Dimitrakopoulos, 2018; Singh \& Sinha, 2020), the constructs, perceived usefulness, perceived ease of use and social influence have no direct relationship to behavioural intention. Thus, hypotheses $\mathrm{H} 3, \mathrm{H} 5$ and $\mathrm{H} 6$ were supported, while $\mathrm{H} 1, \mathrm{H} 2$ and $\mathrm{H} 4$ were not supported. Furthermore, $\mathrm{PU}(\beta=0.430, p<0.001)$, PEOU $(\beta=0.142, p<0.05)$ and SI $(\beta=0.242, p<0.001)$ were significantly related to TR, while there was no significant impact of PC and PI on TR. Therefore, hypotheses $\mathrm{H} 1 \mathrm{a}, \mathrm{H} 2 \mathrm{a}$ and H4a were supported, and H3a and H5a were not.

The outcomes of the hypothesized relationships for testing the mediating effect of trust are summarized in Table 6 . The results of the mediation followed the procedures recommended by Preacher \& Hayes $(2004,2008)$. The table reveals that the mediating effect of trust is supported in $\mathrm{H} 7 \mathrm{a}, \mathrm{H} 7 \mathrm{~b}$ and $\mathrm{H} 7 \mathrm{~d}$. Significant indirect effects were indicated by PU $\rightarrow \mathrm{TR} \rightarrow \mathrm{BI}(\beta=0.199, p<0.001, \mathrm{t}=4.456), \mathrm{PEOU} \rightarrow \mathrm{TR} \rightarrow \mathrm{BI}(\beta=$ $0.066, p<0.05, \mathrm{t}=2.215)$, and SI $\rightarrow \mathrm{TR} \rightarrow \mathrm{BI}(\beta=0.112, p<0.01, \mathrm{t}=3.302)$. Zhang et al. (2019) reportedly found TR to partially mediate the relationship between PU and BI. Contrary to this study, the authors found no mediation effect between PEOU and BI (Zhang et al., 2019). A plausible reason could be that respondents expect CAV 
technology to be user-friendly and easy to navigate. In a similar study, Schmidthuber et al. (2018) suggest SI affects BI positively. We extended their literature to include trust to find the mediating effect. Trust partially mediates the relationship between SI and BI. Finally, the findings found no mediation effect for the constructs, perceived compatibility and personal innovativeness; hence, hypotheses $\mathrm{H} 7 \mathrm{c}$ and $\mathrm{H} 7 \mathrm{e}$ were not supported.

Table 5: Hypotheses Tests

\begin{tabular}{llcccccc}
\hline H & Relationship & Std Beta & Std Error & t-value & p-value & BCI LL & BCI UL \\
\hline H1 & PU $\rightarrow$ BI & 0.009 & 0.067 & 0.134 & 0.894 & -0.122 & 0.136 \\
H2 & PEOU $\rightarrow$ BI & 0.064 & 0.067 & 0.956 & 0.340 & -0.053 & 0.208 \\
H3 & PC $\rightarrow$ BI & 0.271 & 0.088 & 3.082 & 0.002 & 0.087 & 0.425 \\
H4 & SI $\rightarrow$ BI & -0.018 & 0.077 & 0.232 & 0.816 & -0.15 & 0.128 \\
H5 & PI $\rightarrow$ BI & 0.145 & 0.059 & 2.478 & 0.014 & 0.035 & 0.249 \\
H6 & TR $\rightarrow$ BI & 0.463 & 0.08 & 5.782 & 0.000 & 0.301 & 0.609 \\
H1a & PU $\rightarrow$ TR & 0.43 & 0.05 & 8.613 & 0.000 & 0.322 & 0.522 \\
H2a & PEOU $\rightarrow$ TR & 0.142 & 0.058 & 2.449 & 0.015 & 0.027 & 0.255 \\
H3a & PC $\rightarrow$ TR & 0.123 & 0.083 & 1.483 & 0.139 & -0.03 & 0.289 \\
H4a & SI $\rightarrow$ TR & 0.242 & 0.064 & 3.763 & 0.000 & 0.125 & 0.38 \\
H5a & PI $\rightarrow$ TR & 0.07 & 0.061 & 1.144 & 0.253 & -0.054 & 0.182 \\
\hline
\end{tabular}

Noted: $\mathrm{H}$ = hypothesis; $\mathrm{BI}=$ behavioural intention; $\mathrm{PC}=$ perceived compatibility; $\mathrm{PEOU}=$ perceived ease of use; $\mathrm{PI}=$ personal innovativeness; $\mathrm{PU}=$ perceived usefulness; $\mathrm{SI}=$ social influence; $\mathrm{TR}=$ trust

Table 6: Mediation Effects of Trust

\begin{tabular}{llcccccc}
\hline H & Relationship & Std Beta & Std Error & t-value & p-value & BCI LL & BCI UL \\
\hline H7a & PU $\rightarrow$ TR $\rightarrow$ BI & 0.199 & 0.045 & 4.456 & 0.000 & 0.119 & 0.299 \\
H7b & PEOU $\rightarrow$ TR $\rightarrow$ BI & 0.066 & 0.03 & 2.215 & 0.027 & 0.011 & 0.133 \\
H7c & PC $\rightarrow$ TR $\rightarrow$ BI & 0.057 & 0.041 & 1.39 & 0.165 & -0.011 & 0.145 \\
H7d & SI $\rightarrow$ TR $\rightarrow$ BI & 0.112 & 0.034 & 3.302 & 0.001 & 0.055 & 0.193 \\
H7e & PI $\rightarrow$ TR $\rightarrow$ BI & 0.032 & 0.029 & 1.103 & 0.271 & -0.028 & 0.084 \\
\hline
\end{tabular}

Note: $\mathrm{H}=$ hypothesis; $\mathrm{BI}=$ behavioural intention; $\mathrm{PC}=$ perceived compatibility; $\mathrm{PEOU}=$ perceived ease of use; PI = personal innovativeness; $\mathrm{PU}=$ perceived usefulness; $\mathrm{SI}=$ social influence; $\mathrm{TR}=$ trust

\section{Importance-performance map analysis (IPMA)}

Figure 3 presents the importance-performance map, illustrating the importance and performance of each predictor variable on behavioural intention to accept 5G-CAV. Although trust and perceived compatibility have higher importance than the rest of the predictors, they score lower in performance than perceived ease of use and personal innovativeness. This means that trust has the highest importance in predicting the performance of behavioural intention, followed by perceived compatibility. A one-unit change of importance in the trust will result in about $51 \%$ improvement in behavioural intention, while a unit change in perceived compatibility will bring about $34 \%$ increase in intention. This implies that marketers need to enhance further trust in $5 \mathrm{G}$ vehicles as well as strengthening the customers' perceived compatibility with the product, as these two variables have the greatest importance on performance acceptance of 5G CAVs. Social influence is the least important in affecting performance in behavioural intention. 
Figure 3: Importance-Performance Map

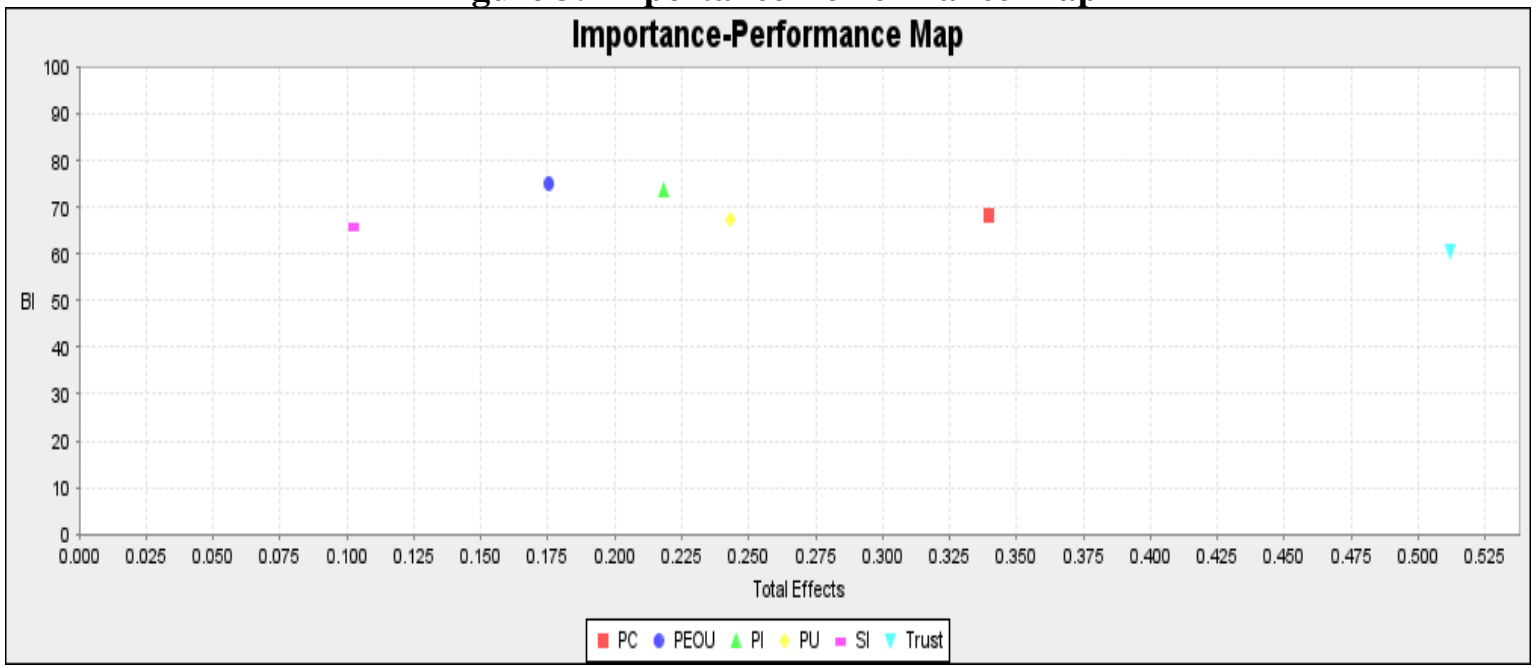

\section{Discussion}

This study was conducted to examine factors that affect 5G CAV technology acceptance. The results confirm the effectiveness of TAM and UTAUT frameworks in explaining technology acceptance behaviour for users within the autonomous vehicle context.

Perceived compatibility and personal innovation were found to have a positive influence on behavioural intention in this research model. Perceived compatibility with autonomous technology is based on how a respondent believes the technology could fit into their existing values, needs and experiences (Rahman et al., 2018; Schmidthuber et al., 2018). It can be implied that respondents believe that CAV technology could fit into their daily lifestyles, replacing the conventional vehicle as a transportation option.

Next, personal innovativeness relates to an individual's readiness to adopt new technology when it becomes available (Rahman et al., 2018). Other researchers have highlighted that innovative users, particularly information and new ideas seekers, will most likely adopt innovative technologies (Lu et al., 2005; Mahat et al., 2012; Shaw \& Sergueeva, 2019). Statistically, this study shows that more than $80 \%$ of respondents are younger than 40 years. Younger and technology savvy people generally show more interest in AV technology (Raue et al., 2019).

Trust exhibits a strong direct effect on behavioural intention. This confirms the results from an existing study of trust in relation to technology acceptance (Gao \& Bai, 2014; Amaro \& Duarte, 2015; Singh \& Sinha, 2020). In the context of the autonomous vehicle, past researchers (Choi \& Ji, 2015; Khastgir et al., 2018; Zhang et al., 2019) suggest that information pertaining the safety and reliability of AV technology should be easily accessible to gain user trust and public acceptance of the technology.

Contrary to findings from past researchers (Davis, 1989; Venkatesh et al., 2003; Gao \& Bai, 2014; Koul \& Eydgahi, 2018; Schmidthuber et al., 2018; Panagiotopoulos \& Dimitrakopoulos, 2018; Singh \& Sinha, 2020), PU, PEOU and SI were found to have no relationship with behavioural intention in this study. Instead, this relationship was 
found to be partially mediated by trust.

In a review of our findings, we found the mediation effect of trust on perceived usefulness and intention to use. Similar to findings from Zhang et al. (2019), this implies that people will develop higher trust when they believe they can benefit from using CAV technology. Respondents believe that enhanced 5G CAV technology will allow them to reach their destination faster, more conveniently, efficiently, and safely.

A prior study found that trust has no mediating effect on PEOU with the intention to use (Ghazizadeh et al., 2012; Zhang et al., 2019). However, in this study, trust was found to mediate the relationship between perceived ease of use and behavioural intention. A possible explanation is that respondents expect functional simplicity in autonomous vehicle technology. Complexity in the functional design of the autonomous technology will increase uncertainty and doubt in the capability of CAV.

Social influence is how an individual perceives the importance of others' opinions in engaging autonomous vehicle technology (Hewitt et al., 2019). In this study, social influence was perceived to affect trust and leads to behavioural intention to use CAV. Various researchers (Gao \& Bai, 2014; Panagiotopoulos \& Dimitrakopoulos, 2018) found that influences from others, mass media and testimonials alike could affect trust and the likelihood to adopt the technology.

Similarly, Sharpton et al. (2020) also suggest that people may feel distrust when important information is not reliable; thus, leading to a decrease in public acceptance. For example, a recent fatal accident involving Uber and Google driverless cars created a poor public perception of autonomous technology (Yu \& Petnga, 2018). Such a misconception can reduce trust in CAV and should be addressed by automobile manufacturers and policymakers as soon as possible.

\section{Theoretical Implications}

The extended model has shown that perceived compatibility and personal innovativeness could influence behavioural intention. In the past, these constructs show a positive result in the area of internet services, mobile commerce and online learning (Lu et al., 2005; Mahat et al., 2012; Schmidthuber et al., 2018; Shaw \& Sergueeva, 2019). There is very little evidence that explains the relationship between these constructs and behavioural intention in the context of autonomous technology. Hence this study contributes to the literature by showing that in the context of CAV technology, compatibility and innovativeness significantly influence behavioural intention. Furthermore, trust has significantly impacted the acceptance of technology.

Findings suggest that respondents trust CAV as they perceive the technology to be useful, enabling them to travel to a destination faster, safer, and stress-free. Also, respondents expect the interaction experience with CAV to be easy; thus, enhancing their trust level. The results also show that respondents perceive social influence as an important factor in building trust in CAV technology. Overall, we may conclude that trust was a strong determinant of behavioural intention. Therefore, future studies on technology acceptance should include the construct of trust to understand its effect on behavioural intention. 


\section{Managerial Implications}

This study provides some key factors in the adoption of 5G CAV technology in Malaysia. The results of this study and the IPMA revealed the importance of trust in getting the consumer to adopt CAV technology. CAV manufacturers should prioritize the safety features in technology and minimize the design's complexity. Furthermore, manufacturers should be more open and transparent in promoting the vehicle through social media, websites, marketing, press releases and proactively addressing all concerns in CAV technology. By doing so, manufacturers could develop consumer trust in their brand.

The development of CAV technologies around the world is facing some challenges concerning driving regulatory and the liability risk (Zhao et al., 2018). For instance, CAV manufacturers face potential product liability risk when individuals or property are damaged by or in circumstances surrounding autonomous vehicles. Another issue is the risk of data privacy and cybersecurity breaches in the CAV industry. Such issues become an obstacle to technology innovation. Hence, policymakers need to provide guidelines for a consistent regulatory approach to prioritize safety and promote innovation in CAV technology.

Also, based on the IPMA, marketers should promote the 5G CAVs image as a personification of a customer's personality, taste and preference. The majority of them are in the 25 to 40-year-old group, earning about RM8000 per month, so advertisements should, therefore, be enhanced to reach this group of buyers. Managers should ignore attempts to increase the importance of social influence in their marketing strategy, as it will not result in better performance in behavioural intention to purchase the $5 \mathrm{G}$ vehicles.

\section{Limitations and Further Research Directions}

This study has several limitations that may open new insight to further research. First of all, this study uses an autonomous driving bus developed by the Yutong Group in China (China Car News, 2019) to reference CAV technology. The study may or may not represent the autonomous vehicle, in general. Respondents may have a different opinion between an autonomous driving bus with other vehicles, such as autonomous cars, trucks or trains. Also, the survey instructions did not provide any reference to the actual capabilities of CAV technology in terms of safety, speed and benefits. As 5G CAV technology is not commercially available in Malaysia, all data collected from this research were based on the respondents' perception of the autonomous technology. Hence, further study on CAV acceptance may yield more interesting results when people become more familiar with the technology (Bernard et al., 2019; Zhang et al., 2019).

Generally, it could be implied that people are becoming more environmentally conscious of their surroundings. CAV technology, if implemented correctly, could help reduce carbon emissions and significantly improve the environment (Chehri \& Mouftah, 2019). A study from Herrenkind et al. (2019) suggests that people could be unaware or distrust that autonomous technology could impact the ecological footprint. Hence, a future study on CAV technology adoption may include the construct of 
environmental awareness as a mediating variable to understand how it could impact consumer behavioural intention.

\section{Practical Implications for Asian Business}

Globalization and technological advancement have brought rapid changes to the transportation sector. As the population grows faster in urban areas, the development of urban transportation has become a challenge. In recent years, growing awareness and interest in environmental sustainability has increased demand for greener solutions in mobility. The use of the autonomous vehicle was expected to bring huge impacts on travel demands, infrastructure and energy consumption. Research on autonomous vehicle technology suggests a positive demand and acceptance in various countries like the United States, China, Japan and parts of European countries (Koul \& Eydgahi, 2018; Park et al.,2018; Zhao et al., 2018; Penmetsa et al., 2019; Raue et al., 2019; Shin et al., 2019). The autonomous vehicle is expected to create new business models in the mobility service market. According to an estimation by the Intel Corporation and Strategy Analytics, autonomous vehicle technology might produce economic benefits worth $\$ 7$ trillion by 2050 (Intel, 2019).

In the context of the Asian market, the autonomous vehicle could potentially create new business models through on-demand mobility with carmakers as the transportation service providers. With the emergence of $5 \mathrm{G}$ network connectivity, people can now have faster and broader access to internet services. Consumers can order mobility whenever and wherever they need to go. This also means the autonomous vehicle industry could provide wider services to a broader scope of users like people with disabilities, people without a driving license, older people and other consumers who could enjoy the convenience of the automobile without physically owning or operating one. Carmakers can offer self-driving subscription services, where the customer pays a recurring fee for the right to use the autonomous vehicle at their convenience. Other potential services, like in-flight entertainment and productive software, can also be unlocked through subscription-based services.

Although the transition to autonomous vehicles could potentially affect conventional driving jobs such as truck delivery, bus and taxi drivers, the autonomous vehicle industry could also create new job opportunities. Driver-free technology means more resources can be saved for other uses. For example, drivers can be retrained to engage consumers in other higher-skilled tasks like remote autonomous vehicle operators who provide real-time driving assistance support. Pilotless vehicles could provide passenger with free time to embrace their favourite online activities, such as social networking, video streaming and online purchasing. Thus, more jobs on sales and customer services can be created to approach consumers through fully personalized location-based marketing.

From the socioeconomic aspect, CAV technology could increase productivity by improving traffic safety, reducing travel time and costs, reduce fuel consumption and also decrease the need for parking spaces. Andersson \& Ivehammar (2019) suggest that CAV could reduce emissions on the roads, representing a reduction in fuel consumption by at least $25 \%$ for vehicles. Also, a study in Singapore shows that the cost per passenger $/ \mathrm{km}$ for using autonomous vehicles was estimated to be $50 \%$ lower than the 
conventional counterparts (Ongel et al., 2019). Although the initial acquisition cost of owning an autonomous vehicle is high, it is assumed that lower fuel costs and less maintenance frequency could compensate for the long-term usage.

Despite the benefits above of autonomous technology, CAV industries are unable to grow without clear regulations and standards from the government (Bartolini et al., 2017). Government plays a major role in exploring regulations like safety protection, cybersecurity and data privacy to shape the future for the autonomous vehicle. Also, by taking an active role in defining new regulations and enhancing the existing legal framework, new markets and industries related to the technology will be developed.

\section{References}

Andersson, P., \& Ivehammar, P. (2019), Benefits and Costs of Autonomous Trucks and Cars. Journal of Transportation Technologies, 09(02), 121-145.

Aptiv, (2019), "MOBILITY NOW: How Autonomous Vehicles Can Help Pave the Way for Smarter Cities", Retrieved from https://www.aptiv.com/media/article/mobility-nowhow-autonomous-vehicles-can-help-pave-the-way-for-smarter-cities

Bartolini, C., Tettamanti, T. and Varga, I. (2017), Critical features of autonomous road transport from the perspective of technological regulation and law. Transportation Research Procedia, 27, pp.791-798.

BBC News, (2019), "Will 5G be necessary for self-driving cars?", Retrieved from https://www.bbc.com/news/business-45048264

Bernard Bracy, J., Bao, K. and Mundy, R., 2019, Highway infrastructure and safety implications of AV technology in the motor carrier industry. Research in Transportation Economics, 77, p.100758.

Borneo Post Online, (2018), "Malaysia on track to complete autonomous vehicle R\&D by 2025 | Borneo Post Online", Retrieved from https://www.theborneopost.com/2018/03/22/malaysia-on-track-to-completeautonomous-vehicle-rd-by-2025/

Chawla, D. and Joshi, H., (2020), The moderating role of gender and age in the adoption of mobile wallet. Foresight, ahead-of-print(ahead-of-print).

Chehri, A. and Mouftah, H., (2019), Autonomous vehicles in the sustainable cities, the beginning of a green adventure. Sustainable Cities and Society, 51, p.101751.

Chen, S., Yen, D. and Peng, S., (2018), Assessing the impact of determinants in e-magazines acceptance: An empirical study. Computer Standards \& Interfaces, 57, pp.49-58.

China Car News, (2019), "No Cockpit and Steering Wheel, Yutong L4 Automatic Driving Bus "Xiaoyu" on Road Trial - Chinapev.com. ", Retrieved from https://www.chinapev.com/yutong/no-cockpit-and-steering-wheel-yutong-14automatic-driving-bus-xiaoyu-on-road-trial/

Choi, J. and Ji, Y., (2015), Investigating the Importance of Trust on Adopting an Autonomous Vehicle. International Journal of Human-Computer Interaction, 31(10), pp.692-702.

Comrey, A. and Lee, H., (1992), A first course in factor analysis. 2nd ed. Hillsdale, New Jersey: Lawrence Erlbaum Associates, Publishers, p.271.

Davis, F., (1989), Perceived Usefulness, Perceived Ease of Use, and User Acceptance of Information Technology. MIS Quarterly, 13(3), p.319.

Davis, F., Bagozzi, R. and Warshaw, P., (1989), User Acceptance of Computer Technology: A Comparison of Two Theoretical Models. Management Science, 35(8), pp.982-1003.

Davis, F. and Venkatesh, V., (1996), A critical assessment of potential measurement biases in the technology acceptance model: three experiments. International Journal of HumanComputer Studies, 45(1), pp.19-45. 
Din, S., Paul, A. and Rehman, A., (2019), 5G-enabled Hierarchical architecture for softwaredefined intelligent transportation system. Computer Networks, 150, pp.81-89.

Eusofe, Z. and Evdorides, H., (2017), Assessment of road safety management at institutional level in Malaysia: A case study. IATSS Research, 41(4), pp.172-181.

Galinina, O., Andreev, S., Komarov, M. and Maltseva, S., (2017), Leveraging heterogeneous device connectivity in a converged 5G-IoT ecosystem. Computer Networks, 128, pp.123-132.

Gao, L. and Bai, X., (2014), A unified perspective on the factors influencing consumer acceptance of internet of things technology. Asia Pacific Journal of Marketing and Logistics, 26(2), pp.211-231.

Ghazizadeh, M., Lee, J. and Boyle, L., (2012), Extending the Technology Acceptance Model to assess automation. Cognition, Technology \& Work, 14(1), pp.39-49.

Hair, J. F., Black, W. C., Babin, B. J., \& Anderson, R. E., (2014), Multivariate data analysis.

Hair, J. F., Hult, G. T. M., Ringle, C., \& Sarstedt, M., (2017), A Primer on Partial Least Squares Structural Equation Modeling (PLS-SEM). Los Angeles: SAGE Publications.

Herrenkind, B., Brendel, A., Nastjuk, I., Greve, M., \& Kolbe, L., (2019), Investigating end-user acceptance of autonomous electric buses to accelerate diffusion. Transportation Research Part D: Transport and Environment, 74, 255-276.

Hewitt, C., Politis, I., Amanatidis, T., and Sarkar, A., (2019), Assessing Public Perception of Self-Driving Cars: The Autonomous Vehicle Acceptance Model. Proceedings of the 24th International Conference on Intelligent User Interface, pp.518-527.

Hulse, L., Xie, H. and Galea, E., (2018), Perceptions of autonomous vehicles: Relationships with road users, risk, gender and age. Safety Science, 102, pp.1-13.

Intel, (2019), "Intel and the Emerging Passenger Economy", Retrieved from https://www.intel.com/content/www/us/en/automotive/passenger-economy-reportautonomous-driving-document.html

Llanasas, R., (2019), “5G's Important Role in Autonomous Car Technology”, Retrieved from https://www.machinedesign.com/motion-control/5g-s-important-role-autonomouscar-technology [Accessed 1 Nov. 2019].

Kaur, K., \& Rampersad, G., (2018), Trust in driverless cars: Investigating key factors influencing the adoption of driverless cars. Journal of Engineering and Technology Management, 48, 87-96.

Khastgir, S., Birrell, S., Dhadyalla, G., \& Jennings, P., (2018), Calibrating trust through knowledge: Introducing the concept of informed safety for automation in vehicles. Transportation Research Part C: Emerging Technologies, 96, 290-303.

Koul, S. and Eydgahi, A., (2018), Utilizing Technology Acceptance Model (TAM) for connected autonomous vehicle technology Adoption. Journal of technology management \& innovation, 13(4), pp.37-46.

Liu, P., Xu, Z. and Zhao, X., (2019), Road tests of self-driving vehicles: Affective and cognitive pathways in acceptance formation. Transportation Research Part A: Policy and Practice, 124, pp.354-369.

Lu, J., Yao, J. and Yu, C., (2005), Personal innovativeness, social influences and adoption of wireless Internet services via mobile technology. The Journal of Strategic Information Systems, 14(3), pp.245-268.

Mahat, J., Ayub, A., Luan, S. \& Wong (2012), An Assessment of Students' Mobile SelfEfficacy, Readiness and Personal Innovativeness towards Mobile Learning in Higher Education in Malaysia. Procedia - Social and Behavioral Sciences, 64, pp.284-290.

Martínez-Díaz, M. \& Soriguera, F, (2018), Autonomous vehicles: theoretical and practical challenges. Transportation Research Procedia, 33, pp.275-282.

McKinsey \& Company, (2019), "Development in the mobility technology ecosystem--how can 5G help?" , Retrieved from https://www.mckinsey.com/industries/automotive-andassembly/our-insights/development-in-the-mobility-technology-ecosystem-how-can5g-help [Accessed 21 Oct. 2019]. 
Moore, G., \& Benbasat, I., (1991), Development of an Instrument to Measure the Perceptions of Adopting an Information Technology Innovation. Information Systems Research, 2(3), 192-222.

New China TV, (2019), "5G driverless smart bus on trial runs in Zhengzhou, China", Retrieved from https://www.youtube.com/watch?v=97jA9fGjHok

Nordhoff, S., de Winter, J., Kyriakakis, M., van Arem, B. and Happee, R., (2018), Acceptance of Driverless Vehicles: Results from a Large Cross-National Questionnaire Study. Journal of Advanced Transportation, 2018, pp.1-22.

Ongel, A., Loewer, E., Roemer, F., Sethuraman, G., Chang, F., \& Lienkamp, M., (2019), Economic Assessment of Autonomous Electric Microtransit Vehicles. Sustainability, 11(3), 648.

Panagiotopoulos, I. and Dimitrakopoulos, G., (2018), An empirical investigation on consumers' intentions towards autonomous driving. Transportation Research Part C: Emerging Technologies, 95, pp.773-784.

Park, E., Lim, J. and Cho, Y., (2018), Understanding the Emergence and Social Acceptance of Electric Vehicles as Next-Generation Models for the Automobile Industry. Sustainability, 10(3), p.662.

Pei Ling, G., (2017), "Road Accidents Cost Malaysia RM9.2Bil in 2016", Retrieved from https://www.thestar.com.my/news/nation/2017/02/02/road-accidents-cost-malaysiarm9dot2bil-in-2016

Penmetsa, P., Adanu, E., Wood, D., Wang, T. and Jones, S., (2019), Perceptions and expectations of autonomous vehicles - A snapshot of vulnerable road user opinion. Technological Forecasting and Social Change, 143, pp.9-13.

Preacher, K., \& Hayes, A., (2004), SPSS and SAS procedures for estimating indirect effects in simple mediation models. Behavior Research Methods, Instruments, \& Computers, 36(4), 717-731.

Preacher, K., \& Hayes, A., (2008), Asymptotic and resampling strategies for assessing and comparing indirect effects in multiple mediator models. Behavior Research Methods, 40(3), 879-891.

Rahman, M., Strawderman, L., Lesch, M., Horrey, W., Babski-Reeves, K. and Garrison, T., (2018), Modelling driver acceptance of driver support systems. Accident Analysis \& Prevention, 121, pp.134-147.

Rendon Schneir, J., Ajibulu, A., Konstantinou, K., Bradford, J., Zimmermann, G., Droste, H. and Canto, R. (2019). A business case for $5 \mathrm{G}$ mobile broadband in a dense urban area. Telecommunications Policy, 43(7), p.101813.

Raue, M., D'Ambrosio, L., Ward, C., Lee, C., Jacquillat, C. and Coughlin, J., (2019), The Influence of Feelings While Driving Regular Cars on the Perception and Acceptance of Self-Driving Cars. Risk Analysis, 39(2), pp.358-374.

Road Safety Department of Malaysia, (2014), "Road Safety Plan of Malaysia 2014-2020. Putrajaya", http://www.mot.gov.my/SiteCollectionDocuments/Darat/Road_Safety_Plan_20142020_booklet-EN.pdf

Schierz, P., Schilke, O. and Wirtz, B., (2010), Understanding consumer acceptance of mobile payment services: An empirical analysis. Electronic Commerce Research and Applications, 9(3), pp.209-216.

Schmidthuber, L., Maresch, D. and Ginner, M., (2018), Disruptive technologies and abundance in the service sector - toward a refined technology acceptance model. Technological Forecasting and Social Change, p.119328.

Sekaran, U. and Bougie, R., (2016), Research Methods for Business: A Skill Building Approach Seventh Edition. 7th ed. John Wiley \& Sons.

Shankland, S., (2019), "5G could help self-driving cars talk to each other, but new C-V2X tech will help human drivers, too", Retrieved from https://www.cnet.com/news/5g-couldmake-self-driving-cars-smarter-commutes-safer/ 
Sinha, I. and Mukherjee, S., (2016), Acceptance of technology, related factors in use of off branch e-banking: an Indian case study. The Journal of High Technology Management Research, 27(1), pp.88-100.

Sharpton, T., Lawrence, T. and Hall, M., (2020), Drivers and barriers to public acceptance of future energy sources and grid expansion in the United States. Renewable and Sustainable Energy Reviews, 126, p.109826.

Shaw, N. and Sergueeva, K., (2019), The non-monetary benefits of mobile commerce: Extending UTAUT2 with perceived value. International Journal of Information Management, 45, pp.44-55.

Shin, K., Tada, N. and Managi, S., (2019), Consumer demand for fully automated driving technology. Economic Analysis and Policy, 61, pp.16-28.

Singh, N. and Sinha, N., (2020), How perceived trust mediates merchant's intention to use a mobile wallet technology. Journal of Retailing and Consumer Services, 52, p.101894.

Sumaco, F., Imrie, B. and Hussain, K., (2014), The Consequence of Malaysian National Culture Values on Hotel Branding. Procedia - Social and Behavioral Sciences, 144, pp.91-101.

Tabachnick, B. and Fidell, L., (2007), Using Multivariate Statistics. 5th ed. Boston: Pearson Education. Inc., p.613.

Tarhini, A., Hone, K., Liu, X. and Tarhini, T., (2016), Examining the moderating effect of individual-level cultural values on users' acceptance of E-learning in developing countries: a structural equation modeling of an extended technology acceptance model. Interactive Learning Environments, 25(3), pp.306-328.

Tian, D., Gong, W., Liu, W., Duan, X., Zhu, Y., Liu, C. and Li, X., (2018), Applications of intelligent computing in vehicular networks. Journal of Intelligent and Connected Vehicles, 1(2), pp.66-76.

Venkatesh, Morris, Davis, \& Davis., (2003), User Acceptance of Information Technology: Toward a Unified View. MIS Quarterly, 27(3), 425.

Wegman, F., (2017), The future of road safety: A worldwide perspective. IATSS Research, 40(2), pp.66-71.

World Economic Forum, (2019), “Are we ready for self-driving cars?”, Retrieved from https://www.weforum.org/agenda/2015/11/are-we-ready-for-self-driving-cars/ [Accessed 21 Oct. 2019].

Yu, J., \& Petnga, L., (2018), Space-based Collision Avoidance Framework for Autonomous Vehicles. Procedia Computer Science, 140, 37-45.

Zhang, S., Wang, Y. and Zhou, W., (2019), Towards secure 5G networks: A Survey. Computer Networks, 162, p.106871.

Zhang, T., Tao, D., Qu, X., Zhang, X., Lin, R. and Zhang, W., (2019), The roles of initial trust and perceived risk in public's acceptance of automated vehicles. Transportation Research Part C: Emerging Technologies, 98, pp.207-220.

Zhao, J., Liang, B. and Chen, Q., (2018), The key technology toward the self-driving car. International Journal of Intelligent Unmanned Systems, 6(1), pp.2-20. 